George A. King, ${ }^{1}$ and Peter Norberg ${ }^{2}$

\title{
A Methodology for Quantifying the Atmospheric Corrosion Performance of Fabricated Metal Products in Marine Environments
}

Reference: King, G. A., and Norberg, P., “A Methodology for Quantifying the Atmospheric Corrosion Performance of Fabricated Metal Products in Marine Environments," Marine Corrosion in Tropical Environments, ASTM STP 1399, S. W. Dean, G. Hernandez-Duque Delgadillo and J. B. Bushman, Eds., American Society for Testing and Materials, West Conshohocken, PA, 2000.

\begin{abstract}
In Australia a long-term project is studying the marine atmospheric corrosion performance of several metals and alloys, and a range of generic classes of coatings and finishes (metallic and organic) on steel and aluminum. Specimens have been exposed for over nine years at three marine sites, both in the open and under a specially designed glass shelter which has greatly accelerated deterioration. The sheet product test pieces include a range of features designed to simulate the types of distress introduced during manufacture and building, and at which corrosion defects initially manifest. A methodology is described for the development of quantitative performance indices for these formed specimens. The general philosophy involves using the collected data to determine appropriate weighting to different types of defects on features, or to the relative contribution of different features to overall defect indices and in turn their relative contribution to a total performance index. A rigorous mathematical procedure was followed to calculate defect indices and total performance indices for all products. Some results for the two-year specimens are discussed.
\end{abstract}

Keywords: atmospheric corrosion, marine environment, prepainted coated product, coil coating, durability assessment, performance indices, semi-sheltered exposure

\section{Nomenclature}

Types of corrosion defect on coated metal products:

$\begin{array}{ll}\text { WCP } & \text { White Corros } \\ \text { RR } & \text { Red Rusting } \\ \text { BL } & \text { Blistering } \\ \text { UC } & \text { Undercutting }\end{array}$

Features in formed specimens - also used for the ratings at those features in equations with subscripts min and max representing the minimum and maximum values: FS Flat Surface

$\phi \mathrm{t} \quad$ Flat bend in product through 180 degrees

3t Bend in product using mandrel of $3 \times$ thickness

5t $\quad$ Bend in product using mandrel of $5 \times$ thickness

3mm Conical bend of $3 \mathrm{~mm}$ diameter 
20mm Conical bend of $20 \mathrm{~mm}$ diameter

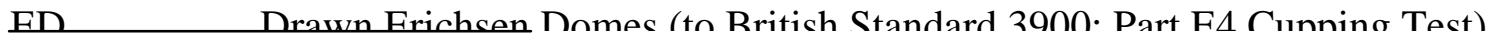

${ }^{1}$ Principal Research Scientist, CSIRO BCE, PO Box 56, Highett, Victoria 3190, Australia.

${ }^{2}$ Royal Institute of Technology, Centre for Built Environment, PO Box 88, SE-801 02 Gävle, Sweden.

VCE Vertical Cut Edge of cover plate adjacent to main panel

$\mathrm{CH} \quad$ Circular Hole

Defect indices for features of specimens, viz. a measure of the defect on that specimen feature:

\begin{tabular}{ll} 
FSI $_{\mathrm{WCP} / \mathrm{RR}}$ & Flat Surface Index for White Corrosion Product and Red Rusting \\
$\mathrm{BI}_{\mathrm{WCP}}$ & Bends Index for White Corrosion Product \\
$\mathrm{BI}_{\mathrm{RR}}$ & Bends Index for Red Rusting \\
$\mathrm{CEI}_{\mathrm{WCP} / \mathrm{RR}}$ & Cut Edge/Scribe Index for White Corrosion Product and Red Rusting \\
$\mathrm{FSI}_{\mathrm{BL}}$ & Flat Surface Index for Blistering \\
$\mathrm{BI}_{\mathrm{BL}}$ & Bends Index for Blistering \\
\multicolumn{1}{c}{ Overall defect indices and product total performance index: } \\
$\mathrm{UCI}_{\mathrm{TOT}}$ & Total Undercutting Index \\
$\mathrm{WCPI}_{\mathrm{TOT}}$ & Total White Corrosion Product Index \\
$\mathrm{RRI}_{\mathrm{TOT}}$ & Total Red Rusting Index \\
$\mathrm{BLI}_{\mathrm{TOT}}$ & Total Blistering Index \\
$\mathrm{TPI}$ & Total Performance Index
\end{tabular}

\section{Introduction}

Prefinished sheet metal products in roll formed profiles are very widely used in the building and construction industries throughout the world. The majority share of the market is occupied by steel, coated with zinc, 5\% aluminum-zinc (Al-Zn), or 55\% Al$\mathrm{Zn}$, either bare or with additional coil painted finishes; however, prepainted aluminum is also extensively used. In 1997 BHP produced 475000 tonnes of 55\% Al-Zn coated steel for the Australian domestic market, with nearly 60\% coil painted [1]. Most Australian construction is close to the coast, and the marine environment represents by far the principal corrosion hazard to all metal products. The need for information on the comparative performance of these generic classes of materials and finishes in part led to the initiation of a long-term exposure program in 1991 with international funding. The original joint sponsors of the project were the International Lead Zinc Research Organisation Inc. (ILZRO), BHP Research (Coated Products Division - Research \& Technology) and Comalco Aluminium Ltd. ILZRO provided assistance in sourcing coated sheet products from the USA, Japan and Germany, and supplies of zinc (USA) and 5\% Al-Zn (Japan) for corrosion rate measurements. BHP provided coated sheet products from Australia and New Zealand, and supplies of 55\% Al-Zn for corrosion rate measurements. Comalco provided coated aluminum sheet products from the USA, and an extrusion in a range of finishes from Australia.

The rationale behind the program, including materials and product selection, the specimen design, and the characteristics of the three exposure sites which also feature a novel semi-sheltered exposure system, has been described in detail previously [2]. 
Twenty commercial sheet products (of four generic types - aluminum, stainless steel with organic topcoat, metallic-coated steel with organic topcoat, and metallic-onlycoated steel) were exposed (with subsequent appraisal to the present methodology) in a program designed to run for 10 years. Only the two-year specimens had been recovered at the time of this evaluation. To give an indication of the very great range in exposure conditions from which the data for this study has been obtained, the levels of chloride deposition (according to ISO 9225 Corrosion of Metals and Alloys - Corrosivity of Atmospheres - Measurement of Pollution) and zinc corrosion rates are given in Table 1. The figures represent a range in severity of conditions by up to a factor of about 17 .

The sheltering system has been found to meet its designed purpose as an accelerated test, and has induced extreme deterioration of most metals and coatings compared to those in open exposure, at the severe and moderate marine sites. The test pieces include a range of features designed to simulate the types of distress introduced into sheet products during manufacture and building, and at which corrosion defects initially manifest. This paper describes in detail the progressive development of a methodology for quantifying the atmospheric corrosion performance of the specimens, taking account of the features in the specimens and the different defect types.

The vast majority of studies describing the exposure and appraisal of coated sheet metal products have used simple specimens, generally with a flat surface only and possible scribing. The issue of incorporating a range of features into test specimens and evaluating the corrosion performance at these, has not been addressed adequately by standards organizations worldwide. The ASTM Test Method for Evaluation of Painted or Coated Specimens Subjected to Corrosive Environments (D 1654) describes the scribing of specimens in detail, but leaves the issue of assessment at deformation features and cut edges to be agreed upon between the producer and user. The US National Coil Coaters Association Technical Bulletin No. III-9, Guidelines for Conducting Exterior Exposure Tests, incorporates a reverse drawn dome, scribe and $180^{\circ}$ bend. The Australian/New Zealand Standard on Performance Requirements of Prefinished/Prepainted Sheet Metal Products for Interior/Exterior Building Applications (AS/NZS 2728:1997) describes a flat panel with optional shaping (3t and 5t bends) and scribing. However, no requirements for the durability of the organic film at the bends of shaped panels are specified.

Nonetheless, attempts have been made in a few studies of the durability performance of coil-coated materials to account for the influence of various features and defects, and calculate performance indices in an objective way. Work in The Netherlands used panels to the ECCA (European Coil Coaters Association) design and converted all estimates of defects to a percentage of the total area or edge length of the panel [3].

By far the most comprehensive attempt to date was a major study carried out about 20 years ago by Johnson and Marsh of the British Steel Corporation [4]. They

Table 1 - Chloride Deposition Levels and Zinc Corrosion Rates for Exposure Sites

\begin{tabular}{llcc}
\hline & & $\begin{array}{c}\text { Chloride Deposition } \\
\left(\mathrm{mg} / \mathrm{m}^{2} . \mathrm{d}\right)\end{array}$ & $\begin{array}{c}\text { One-year Zinc Corrosion Rate } \\
(\mu \mathrm{m} / \mathrm{y})\end{array}$ \\
\hline Severe marine & - Open & 99 & 6.2 \\
& - Sheltered & 70 & 15.2 \\
Moderate marine/rural & - Open & 33 & 1.9 \\
& - Sheltered & 26 & 3.9 \\
Mild marine/urban & - Open & 6 & 1.0 \\
& - Sheltered & 5 & 0.9 \\
\hline
\end{tabular}


emphasized two points: "firstly that conventional testing took no account of design features, and published methods for assessing defects from weathering of coatings (ISO and ASTM) are based on the assumption that defects occur uniformly across a surface." They devised formed panel specimens with variable radius bends, cut edges, overlaps, scribing, an Erichsen Dome and fasteners, and also produced "box-type" specimens using these panels which enabled the study of sheltering and orientation. Corrosion products, blistering and flaking were assessed according to the ISO standards, but apparently undercutting from scribes and cut edges was not. Numerical values were assigned to the severity and extent of defects, and these were multiplied by weighting factors for both design feature and defect type. The weighted values were summed to produce a performance index. A deficiency in this procedure though, and one acknowledged by the authors, is that the weighting factors were chosen subjectively. One aim of the current methodology was to attempt to overcome this aspect of determining an objective quantitative measure of performance. The new approach uses the actual outcome of the defect assessments for the various features, as the basis for determining their relative severity in an objective way. This procedure is assumed to be justified by the fact that the present study comprises a very wide range of products, conditions and defect ratings.

\section{Development of a New Methodology for Quantifying Atmospheric Corrosion Performance of Coated Products}

The procedure followed involves four stages of calculations:

1. Allocation of numerical ratings to defects on all features of specimens, and generation of a database.

2. Determination of the relative contributions of various individual features within feature types (bends, cut edges) for each of the defect indices.

3. Determination of the relative contributions of the feature type indices to overall defect indices for a product.

4. Determination of the relative contributions of the total defect indices to a total performance index for a product by generic type.

\section{Defects and Features of “Formed” Specimens Used for Assessment}

Full details of the formed (bent) specimens have been published previously [2]. A schematic drawing of the specimen showing its features is reproduced here in Figure 1. The product codes from Table 2 of that paper are used here for sake of brevity. The metallic/organic-coated products (I1, I4-I9, B5-B8) were assessed with respect to four types of defect: White Corrosion Products (WCP), Red Rusting (RR), Blistering (BL) and Undercutting (UC). The metallic-only-coated products (I2, I3, B1) were assessed for White Corrosion Products and Red Rusting only. Product B4, fluorocarbon-coated 304 grade stainless steel, was not assessed for White Corrosion Products, and the aluminum products C1-C5 were not assessed for Red Rusting. The numbers of the different types of specimen and the defect assessments performed on them are summarized in Table 2. Two independent (i.e two observers) assessments were made for appropriate defect/ feature combinations for all specimens and the average calculated and used in the mathematical treatment. Assessments of the defect types were made on the specimen 
Bend over mandrel

of variable radius:

$\sim 3 \mathrm{~mm}$ dia. to $\sim 20 \mathrm{~mm}$ dia.

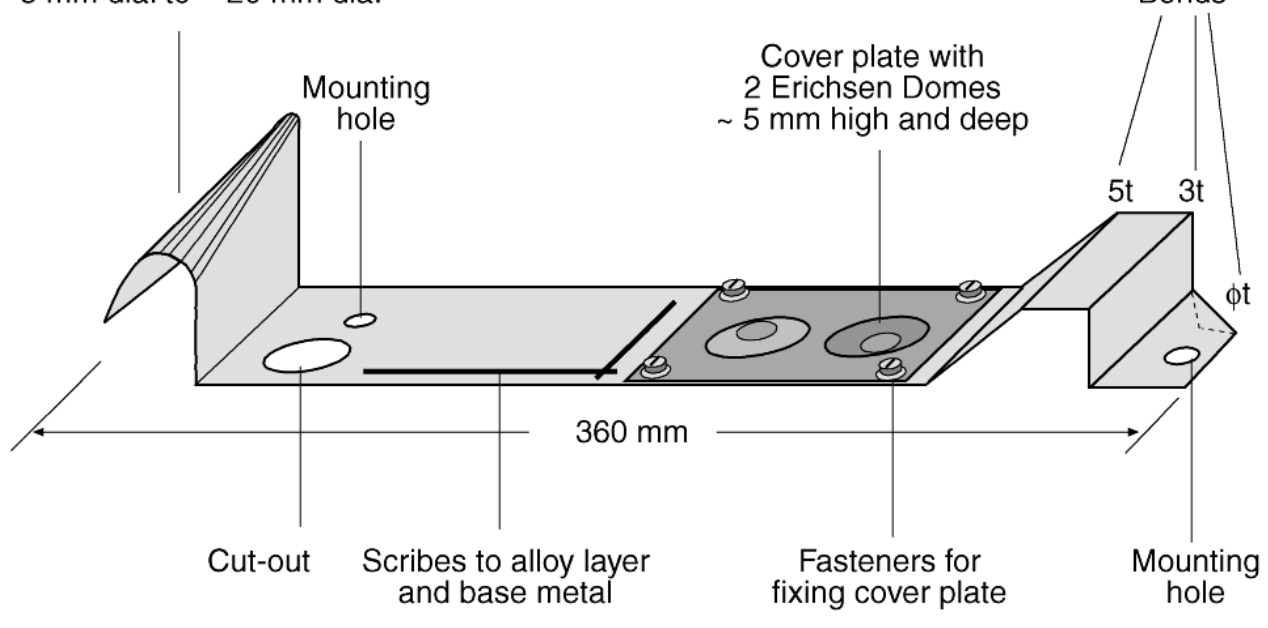

Figure 1 - Schematic of "Formed” Specimen

Table 2 - Numers of Specimens of Different Generic Types and Defect Assessments Performed on Them

\begin{tabular}{cccccc}
\hline $\begin{array}{c}\text { Defect } \\
\text { Type }\end{array}$ & $\begin{array}{c}\text { Metallic-coated } \\
\text { Steel + Organic } \\
\text { Topcoat }\end{array}$ & $\begin{array}{c}\text { Metallic-only } \\
\text { Coated Steel }\end{array}$ & $\begin{array}{c}\text { Stainless Steel } \\
\text { + Organic } \\
\text { Topcoat }\end{array}$ & $\begin{array}{c}\text { Stainless Steel } \\
\text { + Organic } \\
\text { Topcoat }\end{array}$ & $\begin{array}{c}\text { Total Assess- } \\
\text { ments for } \\
\text { Defect Type }\end{array}$ \\
\hline WCP & 66 & 18 & & 30 & 114 \\
RR & 66 & 18 & 6 & & 90 \\
BL & 66 & & 6 & 30 & 102 \\
UC & 66 & & 6 & 30 & 102 \\
\hline
\end{tabular}

the worst rating applicable was chosen as representative of the feature.

Table 3 -Features of "Formed" Specimens Assessed for Different Defect Types 


\begin{tabular}{llll}
\hline & $\begin{array}{c}\text { White Corrosion Products } \\
\text { Red Rusting }\end{array}$ & Blistering & Undercutting \\
\hline Flat Surface & FS & FS & \\
Bends $\quad$ zero t bend & $\phi \mathrm{t}$ & $3 \mathrm{t}$ & \\
$-3 \mathrm{t}$ bend & $3 \mathrm{t}$ & $5 \mathrm{t}$ & \\
$-5 \mathrm{t}$ bend & $5 \mathrm{t}$ & $3 \mathrm{~mm}$ & \\
$\quad-3 \mathrm{~mm}$ diameter conical bend & $3 \mathrm{~mm}$ & $20 \mathrm{~mm}$ & \\
$\quad-20 \mathrm{~mm}$ diameter conical bend & $20 \mathrm{~mm}$ & $\mathrm{ED}$ & $\mathrm{SC}$ \\
Erichsen Domes & ED & & TCE \\
Scribes & SC & BCE \\
Top Cut Edge & TCE & VCE \\
Bottom Cut Edge & BCE & \\
Vertical Cut Edge of cover plate & VCE & & CH \\
$\quad$ adjacent to main panel & & & \\
Circular Hole & & & \\
\hline
\end{tabular}

Criteria for Allocation of Numerical Ratings to Defects

A number of systems exist for rating defects on painted metal products. One is the ISO Paints and Varnishes - Evaluation of Degradation of Paint Coatings - Designation of Intensity, Quantity and Size of Common Types of Defect - Part 1: General Principles and Rating Schemes (ISO 4628/1), Part 2: Designation of Degree of Blistering (ISO 4628/2) and Part 3: Designation of Degree of Rusting (ISO 4628/3). ISO 4628/1 "establishes a general system for designating the intensity, quantity, and size of common types of defects in paint coatings..." It adopts a uniform convention for "designating the intensity and quantity of defects by means of ratings on a numerical scale from 0 to 5,0 denoting no defects and 5 denoting defects so severe that further discrimination has no practical meaning." The ratings from 1 to 4 "are so defined that they give an optimal discrimination over the whole range of the scale.” Three tables give rating schemes for intensity of uniform deterioration, quantity of scattered defects and size of defects. The numerical ratings developed for this study have adhered to the 5-point ISO principles. As a general rule, the means of the two assessments referred to above with a decimal of 0.5 were rounded up to the next integer.

White Corrosion Products - There being no existing international standard for assessment of the extent of White Corrosion Products, an "in-house" rating system used by BHP Coated Products (Port Kembla, Australia) was adopted. This is in exact accord with Table 1 of ISO 4628/1. The rating number is followed by the description of the extent of the defect: 0 zero, 1 very slight, 2 slight, 3 moderate, 4 considerable, 5 severe.

Red Rusting - ISO 4628/3 has pictorial standards for designating the degree of rusting of paint coatings (combination of rust broken through the coating and apparent under-rust). The area rusted in percent for each rating is as follows: $0=0 \%, 1=0.05 \%$, $2=0.5 \%, 3=1 \%, 4=8 \%, 5=40-50 \%$. The ASTM Test Method for Evaluating Degree of Rusting on Painted Steel Surfaces (D610-95) has an 11-point scale for degree of rusting which moves in the opposite direction to ISO 4628/3 and allows for greater discrimination also. ISO 4628/3 presumably is defining the percent area rusted as being "up to" that figure, e.g., rating 1 is for no rust up to $0.05 \%$ rusted area. Rating 5 would then be from $8 \%$ to $40-50 \%$. This does not really enable distinction between say $10 \%$ and $50 \%$ rust. A slightly modified scale is developed here based principally on ISO $4628 / 3$ but taking account of D610. The term "trace" in an assessment is designated a 
percent area of 0.05, and is given a rating of 1. Each independent assessment provided a subjective percentage area affected by red rusting (0-100\%). In general, the average of these figures was calculated and converted to a 5-point rating as follows: Red Rusting index followed by percentage area of rusting on specimens $0=0 \%, 1=>0 \leq 0.05 \%$, $2=>0.05 \leq 1 \%, 3=>1 \leq 8 \%, 4=>8 \leq 40 \%, 5=>40 \%$.

Blistering - Blistering was assessed according to the Australian Standard AS 1580.481.1.9-1991 Paints and Related Materials - Methods of Test. Method 481.1.9: Coatings - Exposed to Weathering - Degree of Blistering. The pictorial standards for blister size and density are the same as for ASTM Test Method for Evaluating Degree of Blistering of Paints (D714-87), but in the Australian Standard the numerical rating has been changed to a 5-point scale in accordance with ISO 4628/2. Blistering is appraised in terms of density and size aSb, where $a$ is the index for density and $b$ is the index for size. A single numerical index is required to enable mathematical calculations (statistical analysis etc.) of the data. This was achieved as follows. The averages of the independent ratings for density and size were evaluated separately and rounded to give a representative rating. These numbers were multiplied together, the square root was taken, and the resulting number was rounded to the nearest integer. Example as follows: rating by operator A is 3S4, by operator B is 4S3. This gives an average rating of 3.5S3.5 which is rounded to $4 \mathrm{~S} 4$. The average indices for size and density are multiplied together to give 16, the square root is 4 ; so the blistering index for that feature is 4 .

Undercutting - ISO 4628 does not specify a rating scale for Undercutting. However, AS 1580.481.3-1992 Paints and Related Materials - Methods of Test: Method 481.3: Coatings - Exposed to Weathering - Degree of Corrosion of Coated Metal Substrates, has a rating scale for assessment of representative mean creepage of underfilm corrosion from a scribed line and panel edge. This scale is in accord with the ISO principle and has been adopted here for assessment of undercutting. This was assessed as an actual range of depths (minimum and maximum) in millimeters by two independent operators. The arithmetic averages of the two minima and maxima were determined and then converted to ratings (min. and max.) again on the 5-point scale from the Australian Standard as follows: Undercutting rating followed by depth $(\mathrm{mm}), 0=0$, $1=>0 \leq 1,2=>1 \leq 3,3=>3 \leq 7,4=>7 \leq 13,5=>13$.

Database of Numerical Ratings - Based on the above criteria, all specimens recovered after exposure for 2 years 29 days were assessed and the average numerical ratings for each defect on the chosen features were calculated for each of the product/exposure condition combinations (20 products $\times 3$ sites $\times$ open/sheltered $=120$ ). The results were entered into an extensive spreadsheet. Table 4 shows part of this spreadsheet, the raw data for six of these combinations, as an example. Three products with similar paint topcoats (polyester or silicon-modified polyester (SMP)) are chosen (I1, B5, C4 - see Ref. 2). They had all been exposed at a severe marine site for 2 years in the open and under the special shelter $(1,2, \mathrm{O}$ and $\mathrm{S}$ respectively as the last three characters in the Specimen ID).

\section{Criteria for Determining the Relative Contribution of Each Individual Feature (Within} Feature Type) to the Defect Indices

The philosophy on which the development of performance indices is based depends on assigning an appropriate weighting to different types of defects on features, 
or the relative contribution of different features to an overall defect index. The "severity" of features is reflected in the defect ratings, which have themselves accordingly been used to derive weighting coefficients. A procedure of inverting and normalizing has been adopted to determine appropriate coefficients for each feature on the basis of their severity. A severe feature is more likely to show a defect and its coefficient should accordingly be smaller. The severity of features is reflected in the database (spreadsheet) of all of the ratings (only a part of which is shown in Table 4 here) which has itself accordingly been used to derive weighting coefficients. The mean values of the defect ratings for each of the "features" of the formed specimens are given in Table 5. These mean values have been calculated from all available data for the 120 product/exposure condition combinations.

Non-zero ratings on all or most features were obtained from about $53 \%$ of specimens for White Corrosion Products, 13\% for Red Rusting, 49\% for Blistering and $69 \%$ for Undercutting. 
Table 4 - Numerical Ratings for Defects on Selected Features of Formed Specimens (This Example is for Three Products with a Polyester or SMP Topcoat Exposed Both in the Open and Sheltered for a Period of Two Years at a Severe Marine Site)

\begin{tabular}{|c|c|c|c|c|c|c|c|c|c|}
\hline & Specimen ID & I1120 & I112S & B5120 & B512S & C4120 & C412S \\
\hline & & & Base Metal & Steel & Steel & Steel & Steel & $\mathrm{Al}$ & $\mathrm{Al}$ \\
\hline & & & Alloy Coating & $5 \% \mathrm{Al}-\mathrm{Zn}$ & $5 \% \mathrm{Al}-\mathrm{Zn}$ & $55 \% \mathrm{Al}-\mathrm{Zn}$ & $55 \% \mathrm{Al}-\mathrm{Zn}$ & - & - \\
\hline & & & Organic Coating & $\begin{array}{l}20 \mu \mathrm{m} \\
\text { SMP }\end{array}$ & $\begin{array}{l}20 \mu \mathrm{m} \\
\text { SMP }\end{array}$ & $\begin{array}{l}20 \mu \mathrm{m} \\
\text { Polyester }\end{array}$ & \begin{tabular}{|l|}
$20 \mu \mathrm{m}$ \\
Polyester
\end{tabular} & $\begin{array}{l}20 \mu \mathrm{m} \\
\text { Polyester }\end{array}$ & $\begin{array}{l}20 \mu \mathrm{m} \\
\text { Polyester }\end{array}$ \\
\hline & \multirow{11}{*}{\multicolumn{2}{|c|}{ 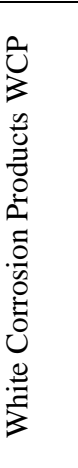 }} & Flat Surface & 2 & 3 & 0 & 0 & 0 & 0 \\
\hline & & & $\phi \mathrm{t}$ bend & 5 & 5 & 2 & 5 & & \\
\hline & & & 3t bend & 2 & 5 & 1 & 2 & 1 & 3 \\
\hline & & & 5t bend & 1 & 5 & 1 & 2 & 0 & 0 \\
\hline & & & Conical $3 \mathrm{~mm}$ & 1 & 4 & 1 & 2 & 0 & 0 \\
\hline & & & Conical $20 \mathrm{~mm}$ & 2 & 4 & 1 & 2 & 0 & 2 \\
\hline & & & Erichsen Domes & 3 & 5 & 1 & 3 & 0 & 0 \\
\hline & & & Scribes & 3 & 5 & 1 & 4 & 0 & 3 \\
\hline & & & Top Cut Edge & 3 & 5 & 2 & 4 & 3 & 3 \\
\hline & & & Bottom Cut Edge & 3 & 5 & 3 & 4 & 3 & 3 \\
\hline & & & $\begin{array}{l}\text { Cover plate/main panel, } \\
\text { Vertical Cut Edge }\end{array}$ & 3 & 5 & 2 & 4 & 2 & 3 \\
\hline \multirow{11}{*}{\multicolumn{2}{|c|}{ 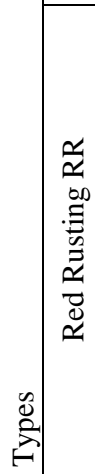 }} & \multirow{11}{*}{ 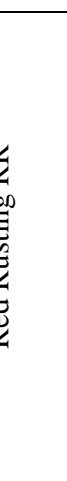 } & Flat Surface & 0 & 0 & 0 & 0 & & \\
\hline & & & $\phi \mathrm{t}$ bend & 0 & 5 & 0 & 0 & & \\
\hline & & & 3t bend & 0 & 0 & 0 & 0 & & \\
\hline & & & 5t bend & 0 & 3 & 0 & 0 & & \\
\hline & & & Conical $3 \mathrm{~mm}$ & 0 & 0 & 0 & 0 & & \\
\hline & & & Conical $20 \mathrm{~mm}$ & 0 & 0 & 0 & 0 & & \\
\hline & & & Erichsen Domes & 0 & 3 & 0 & 0 & & \\
\hline & & & Scribes & 0 & 5 & 0 & 0 & & \\
\hline & & & Top Cut Edge & 0 & 5 & 0 & 0 & & \\
\hline & & & Bottom Cut Edge & 0 & 5 & 1 & 3 & & \\
\hline & & & $\begin{array}{l}\text { Cover plate/main panel, } \\
\text { Vertical Cut Edge }\end{array}$ & 0 & 5 & 0 & 2 & & \\
\hline \multirow{12}{*}{\multicolumn{2}{|c|}{ 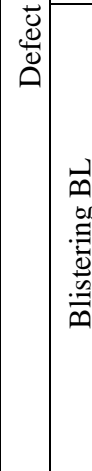 }} & \multirow{6}{*}{ 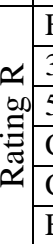 } & Flat Surface & 1S1 & $2 \mathrm{~S} 4$ & 1S2 & 0 & 0 & 1S1 \\
\hline & & & $3 \mathrm{t}$ bend & $5 \mathrm{~S} 1$ & 4S4 & 0 & $4 \mathrm{~S} 2$ & 1S1 & $4 \mathrm{~S} 3$ \\
\hline & & & 5t bend & $4 \mathrm{~S} 1$ & $3 \mathrm{~S} 3$ & 0 & $4 \mathrm{~S} 2$ & 0 & 0 \\
\hline & & & Conical $3 \mathrm{~mm}$ & $2 \mathrm{~S} 1$ & $4 \mathrm{~S} 3$ & 0 & $3 \mathrm{~S} 2$ & 0 & 0 \\
\hline & & & Conical $20 \mathrm{~mm}$ & $3 \mathrm{~S} 1$ & $4 \mathrm{~S} 4$ & 0 & $3 \mathrm{~S} 2$ & 0 & 1S2 \\
\hline & & & Erichsen Domes & $5 \mathrm{~S} 1$ & $3 \mathrm{~S} 4$ & $2 \mathrm{~S} 2$ & $4 \mathrm{~S} 2$ & 0 & 0 \\
\hline & & \multirow{6}{*}{ 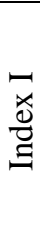 } & Flat Surface & 1 & 3 & 1 & 0 & 0 & 1 \\
\hline & & & 3t bend & 2 & 4 & 0 & 3 & 1 & 3 \\
\hline & & & $5 t$ bend & 2 & 3 & 0 & 3 & 0 & 0 \\
\hline & & & Conical $3 \mathrm{~mm}$ & 1 & 3 & 0 & 2 & 0 & 0 \\
\hline & & & Conical $20 \mathrm{~mm}$ & 2 & 4 & 0 & 2 & 0 & 1 \\
\hline & & & Erichsen Domes & 2 & 3 & 2 & 3 & 0 & 0 \\
\hline \multirow{10}{*}{\multicolumn{2}{|c|}{. }} & \multirow{5}{*}{ 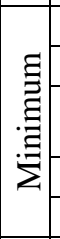 } & Top Cut Edge & 0 & 2 & 0 & 1 & 0 & 0 \\
\hline & & & Bottom Cut Edge & 0 & 3 & 0 & 2 & 0 & 0 \\
\hline & & & $\begin{array}{l}\text { Cover plate/main panel, } \\
\text { Vertical Cut Edge }\end{array}$ & 0 & 3 & 0 & 3 & 0 & 0 \\
\hline & & & Circular Hole & 1 & 2 & 0 & 3 & 0 & 0 \\
\hline & & & Scribes & 0 & 2 & 0 & 1 & 0 & 0 \\
\hline & & & Top Cut Edge & 2 & 3 & 2 & 3 & 1 & 1 \\
\hline & & $\Xi$ & Bottom Cut Edge & 2 & 4 & 3 & 4 & 1 & 1 \\
\hline & & ] & $\begin{array}{l}\text { Cover plate/main panel, } \\
\text { Vertical Cut Edge }\end{array}$ & 2 & 5 & 3 & 5 & 1 & 1 \\
\hline & & & Circular Hole & 2 & 3 & 3 & 3 & 1 & 1 \\
\hline & & & Scribes & 1 & 3 & 2 & 3 & 1 & 2 \\
\hline
\end{tabular}


Table 5 - Mean Values of Defect Ratings for Features of Formed Specimens (for all Available Data for 120 Product/Exposure Condition Combinations)

\begin{tabular}{lccccc}
\hline \multirow{2}{*}{ Feature } & \multicolumn{5}{c}{ Defect Type } \\
\cline { 2 - 6 } & WCP & RR & BL & Min. UC & Max. UC \\
\hline Flat Surface & 0.84 & 0.18 & 0.55 & & \\
$\phi$ t bend & 1.72 & 0.53 & & & \\
3t bend & 1.27 & 0.20 & 1.06 & & \\
5t bend & 0.89 & 0.14 & 0.86 & & \\
Conical 3 mm bend & 0.89 & 0.08 & 0.76 & & \\
Conical 20 mm bend & 0.83 & 0.10 & 0.75 & & \\
Erichsen Domes & 1.04 & 0.26 & 0.97 & & \\
Scribes & 1.88 & 0.70 & & 0.30 & 1.16 \\
Top Cut Edge & 2.17 & 1.18 & & 0.28 & 1.2 \\
Bottom Cut Edge & 2.43 & 1.53 & & 0.47 & 1.62 \\
Vertical Cut Edge & 2.18 & 1.40 & & 0.32 & 1.34 \\
Circular Hole & & & & 0.32 & 1.32 \\
\hline
\end{tabular}

White Corrosion Product/Red Rusting - For White Corrosion Products and Red Rusting the features were considered in three groups: the Flat Surface, the deformed areas (viz. Bends and Erichsen Domes), and the Cut Edges and Scribes (edges of coatings exposed). For each group it was considered that the Feature Index should have a potential maximum value of 100 . This criterion determines the value that the sum of the coefficients must have.

(a) Flat Surface Index - For the Flat Surface the maximum value of a rating is 5 , there is only one coefficient, and the relationship to develop the Index for White Corrosion Product and Red Rusting is:

$$
\text { FSI }_{\mathrm{WCP} / \mathrm{RR}}=20 * \text { Flat Surface Rating (FS) }
$$

(b) Bends Index - For the deformed areas the coefficients for White Corrosion Product to describe the relative importance of each of the bends and the Erichsen Domes were derived by normalizing the mean values of the ratings to the most severe feature $(\phi t$ bend) as follows. The mean value of the WCP rating for the $\phi t, 3 t, 5 t, 3 \mathrm{~mm}$ and $20 \mathrm{~mm}$ bends and for the Erichsen Domes is divided into 1.72 (the value for the $\phi t$ bend itself). The sum of the coefficients must add up to 20. This is achieved by multiplying by 2 and then rounding. The procedure is shown in Table 6 .

Table 6 - Normalizing Rating Values to Determine WCP Feature Coefficients for Deformed Areas

\begin{tabular}{lcccc}
\hline \multicolumn{1}{c}{ Feature } & $\begin{array}{c}\text { Mean Value of } \\
\text { WCP Rating }\end{array}$ & $\begin{array}{c}\text { Divide Mean Value of } \\
\text { WCP Rating into 1.72 }\end{array}$ & Multiply by 2 & Round \\
\hline$\phi$ t bend & 1.72 & 1 & 2 & 2 \\
$3 \mathrm{t}$ bend & 1.27 & 1.35 & 2.7 & 3 \\
$5 \mathrm{t}$ bend & 0.89 & 1.92 & 3.84 & 4 \\
Conical 3 mm bend & 0.89 & 1.94 & 3.87 & 4 \\
Conical 20 mm bend & 0.83 & 2.06 & 4.12 & 4 \\
Erichsen Domes & 1.04 & 1.66 & 3.32 & 3 \\
\hline
\end{tabular}


The relationship to develop the Bends Index for White Corrosion Product is therefore shown below with the abbreviated parameters standing for that rating, i.e., $\phi t$ is $\phi$ t Rating:

$$
\mathrm{BI}_{\mathrm{WCP}}=(2 * \phi \mathrm{t})+(3 * 3 \mathrm{t})+(4 * 5 \mathrm{t})+(4 * 3 \mathrm{~mm})+(4 * 20 \mathrm{~mm})+(3 * \mathrm{ED})
$$

with a potential maximum individual rating at each of the features of 5 , the Bends Index also has a maximum value of 100 . Note that the coefficient on the most severe feature (the $\phi t$ bend) has the lowest value.

For Red Rusting the mean values of the ratings for each of the features yielded a different set of coefficients (for the bend features) to those obtained for the White Corrosion Product. The actual normalized coefficients were as follows: $\phi t=1,3 t=3,5 t$ $=4,3 \mathrm{~mm}=7,20 \mathrm{~mm}=5, \mathrm{ED}=2$. However, as these values were derived from a very small data set (about 12 specimens) it was decided to adopt the same coefficients as for the White Corrosion Product. White Corrosion Product is a "precursor" to Red Rusting, providing an additional reason for adopting the same set of coefficients. The relationship to develop the Bends Index for Red Rusting $\left(\mathrm{BI}_{\mathrm{RR}}\right)$ is therefore the same as Equation 2.

(c) Cut Edge/Scribe Index - A similar procedure was followed normalising the mean values of the ratings to the highest value, and the results are given in Table 7.

The mean values for WCP were derived from 114 specimens and the mean values for RR were derived from 90 specimens, a total of 204 assessments. As with the Bends Index, a uniform set of coefficients was desirable to cover both White Corrosion Product and Red Rusting. The coefficients for WCP were multiplied by 114 and added to the coefficients for RR multiplied by 90 . The totals were divided by 204 to yield a set of coefficients as follows: Scribes 1.69, Top Cut Edge 1.20, Bottom Cut Edge 1.00, Vertical Cut Edge 1.10. These were rounded to values of 2, 1, 1 and 1 respectively. The relationship to develop the Cut Edge/Scribe Index for both White Corrosion Product and Red Rusting (again with a potential maximum value of 100) is shown in Equation 3.

$$
\mathrm{CEI}_{\mathrm{WCP} / \mathrm{RR}}=4(2 * \mathrm{SC}+\mathrm{TCE}+\mathrm{BCE}+\mathrm{VCE})
$$

Blistering - The same procedure as for White Corrosion Product/Red Rusting is followed. The mean values of the ratings at each of the features of the formed specimens and the normalized coefficients are shown in Table 8.

Table 7 - Normalizing Rating Values to Determine WCP/RR Feature Coefficients at Coating Edges

\begin{tabular}{lcccc}
\hline Feature & $\begin{array}{c}\text { Mean Value } \\
\text { of WCP } \\
\text { Rating }\end{array}$ & $\begin{array}{c}\text { Divide Mean Value } \\
\text { of WCP into 2.43 }\end{array}$ & $\begin{array}{c}\text { Mean Value } \\
\text { of RR Rating }\end{array}$ & $\begin{array}{c}\text { Divide Mean } \\
\text { Value of RR into } \\
1.53\end{array}$ \\
\hline Scribes & 1.88 & 1.29 & 0.70 & 2.19 \\
Top Cut Edge & 2.17 & 1.12 & 1.18 & 1.30 \\
Bottom Cut Edge & 2.43 & 1.00 & 1.53 & 1.00 \\
Vertical Cut Edge & 2.18 & 1.11 & 1.40 & 1.10 \\
\hline
\end{tabular}


Table 8 - Normalizing Rating Values to Determine Feature Coefficients for Blistering

\begin{tabular}{lccc}
\hline \multicolumn{1}{c}{ Feature } & Mean Rating & Divide into 1.06 & Round \\
\hline Flat Surface & 0.55 & & \\
3t bend & 1.06 & 1 & 1 \\
5t bend & 0.86 & 1.23 & 1 \\
con 3mm bend & 0.76 & 1.38 & 1 \\
con 20mm bend & 0.75 & 1.42 & 1 \\
Erichsen Domes & 0.97 & 1.09 & 1 \\
\hline
\end{tabular}

(a) Flat Surface Index - For the Flat Surface the maximum value of the rating is again 5, there is again only one coefficient, and the relationship to develop the Flat Surface Index for Blistering is the same as for White Corrosion Products/Red Rusting:

$$
\mathrm{FSI}_{\mathrm{BL}}=20 * \mathrm{FS}
$$

(b) Bends Index - The coefficients for the bends and Erichsen Domes are all unity and the relationship to develop the Bends Index for Blistering again with a potential maximum value of 100 is:

$$
\mathrm{BI}_{\mathrm{BL}}=4 *(3 \mathrm{t}+5 \mathrm{t}+3 \mathrm{~mm}+20 \mathrm{~mm}+\mathrm{ED})
$$

Undercutting - Again the same procedure as for the previous defects is followed. The mean values of the ratings at each of the features (with a highest rating of 1.62) and the normalized coefficients are given in Table 9.

The sum of all of the rounded coefficients is 20 . These values have been used to develop the Total Undercutting Index in one step. As each individual feature can have a maximum rating of 5 , the relationship again yields a potential maximum value of 100:

$$
\begin{aligned}
\mathrm{UCI}_{\mathrm{TOT}}= & \left(4 * \mathrm{TCE}_{\text {min }}\right)+\left(2 * \mathrm{BCE}_{\text {min }}\right)+\left(3 * \mathrm{VCE}_{\min }\right)+\left(3 * \mathrm{CH}_{\text {min }}\right)+\left(3 * \mathrm{SC}_{\text {min }}\right) \\
& +\mathrm{TCE}_{\text {max }}+\mathrm{BCE}_{\text {max }}+\mathrm{VCE}_{\text {max }}+\mathrm{CH}_{\max }+\mathrm{SC}_{\text {max }}
\end{aligned}
$$


for Undercutting

\begin{tabular}{|c|c|c|c|c|c|c|}
\hline \multirow[t]{2}{*}{ Feature } & \multicolumn{3}{|c|}{ Minimum Undercutting } & \multicolumn{3}{|c|}{ Maximum Undercutting } \\
\hline & $\begin{array}{c}\text { Mean } \\
\text { Rating }\end{array}$ & $\begin{array}{c}\text { Divide into } \\
1.62 \rightarrow \mathrm{A}\end{array}$ & $\begin{array}{c}\mathrm{A} \times 0.65 \\
\text { and Round }\end{array}$ & $\begin{array}{c}\text { Mean } \\
\text { Rating }\end{array}$ & $\begin{array}{c}\text { Divide into } \\
1.62 \rightarrow \mathrm{A}\end{array}$ & $\begin{array}{c}\mathrm{A} \times 0.65 \\
\text { and Round }\end{array}$ \\
\hline Top Cut Edge & 0.28 & 5.69 & 4 & 1.20 & 1.35 & 1 \\
\hline $\begin{array}{l}\text { Bottom Cut } \\
\text { Edge }\end{array}$ & 0.47 & 3.44 & 2 & 1.62 & 1.00 & 1 \\
\hline $\begin{array}{l}\text { Vertical Cut } \\
\text { Edge }\end{array}$ & 0.32 & 5.00 & 3 & 1.34 & 1.20 & 1 \\
\hline Circular Hole & 0.32 & 5.00 & 3 & 1.32 & 1.22 & 1 \\
\hline Scribes & 0.30 & 5.32 & 3 & 1.16 & 1.40 & 1 \\
\hline
\end{tabular}

Determining Relative Contributions of Feature Type Indices to Overall Defect Indices for a Product

White Corrosion Product - Over 114 specimens, the mean WCP indices for the Flat Surfaces, Bends and Cut Edges are respectively 16.8, 20.4 and 42.1. The overall WCP Index is to have a potential maximum value of 100. As incidence of WCP is greatest on the Cut Edges and least on the Flat Surface (the least severe feature), the overall relationship to account for the relative contributions of the features should reflect this and emphasize the occurrence of the WCP defect on the Flat Surface. The same process of normalization is followed as before by dividing each of the mean indices into the highest value to yield coefficients of Flat Surfaces 2.50, Bends 2.06, Cut Edges 1. These coefficients are converted to decimal fractions, maintaining relativity such that their sum equals 1 , by multiplying by $0.18[1 /(2.50+2.06+1.00)]$. The overall relationship to determine the relative contributions of the Flat Surfaces, Bends and Cut Edges to the Total White Corrosion Product Index is:

$$
\mathrm{WCPI}_{\mathrm{TOT}}=0.45 \mathrm{FSI}_{\mathrm{WCP}}+0.37 \mathrm{BI}_{\mathrm{WCP}}+0.18 \mathrm{CEI}_{\mathrm{WCP}}
$$

Red Rusting - Over 90 specimens, the mean RR indices for the Flat Surfaces, Bends and Cut Edges are respectively 3.6, 3.7 and 22.0. However, it should be noted the Flat Surface Index is based on only 7 non-zero readings, the Bends index on only 17 non-zero readings and the Cut Edge Index on 55 non-zero readings; these are much smaller samples than for the WCP (equivalent numbers Flat Surfaces 45, Bends 79, Cut Edges 114). Normalization is followed as before to yield coefficients for Flat Surfaces 6.20, Bends 5.92, Cut Edges 1. These coefficients are converted to decimal fractions maintaining relativity by multiplying by $0.0762[1 /(6.20+5.92+1.00)]$. The overall relationship to determine the relative contributions of the Flat Surfaces, Bends and Cut Edges to the Total Red Rusting Index is:

$$
\mathrm{RRI}_{\mathrm{TOT}}=0.47 \mathrm{FSI}_{\mathrm{RR}}+0.45 \mathrm{BI}_{\mathrm{RR}}+0.08 \mathrm{CEI}_{\mathrm{RR}}
$$

Blistering - Over 102 specimens, the mean BL indices for the Flat Surfaces and the Bends are respectively 11.0 and 17.6. The Flat Surface Index is based on 32 non-zero readings, the Bends Index on 49 non-zero readings. Normalization is followed as before 
to yield coefficients of 1.60 and 1 which are converted to decimal fractions maintaining relativity such that their sum equals 1 by multiplying by $0.3846[1 /(1.60+1)]$. The overall relationship to determine the relative contributions of the Flat Surface and Bends to the Total Blistering Index is:

$$
\mathrm{BLI}_{\mathrm{TOT}}=0.62 \mathrm{FSI}_{\mathrm{BL}}+0.38 \mathrm{BI}_{\mathrm{BL}}
$$

Contribution of Features to Total Defect Indices - Using the above relationships, the spreadsheet package was used to calculate the Total Indices for White Corrosion Product, Red Rusting and Blistering. Table 10 gives the component and total indices for the same 6 product/exposure condition combinations as in Table 4.

Table 10 - Calculated Indices for All Defect Types on Individual Features, and Total Defect Indices (Example for 6 Product/Exposure Condition Combinations)

\begin{tabular}{|c|c|c|c|c|c|c|c|}
\hline & Specimen ID & $\mathrm{I} 112 \mathrm{O}$ & I112S & B512O & B512S & $\mathrm{C} 412 \mathrm{O}$ & C412S \\
\hline \multirow{4}{*}{ 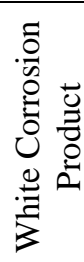 } & WCP FS-Index & 40.0 & 60.0 & 0 & 0 & 0 & 0 \\
\hline & WCP B-Index & 41.0 & 92.0 & 22.0 & 49.0 & 3.0 & 17.0 \\
\hline & WCP CE-Index & 60.0 & 100 & 36.0 & 80.0 & 32.0 & 60.0 \\
\hline & WCP Total Index & 44.0 & 79.0 & 14.6 & 32.5 & 6.9 & 17.1 \\
\hline \multirow{4}{*}{ 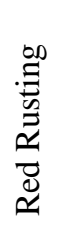 } & RR FS-Index & 0 & 0 & 0 & 0 & & \\
\hline & RR B-Index & 0 & 31.0 & 0 & 0 & & \\
\hline & RR CE-Index & 0 & 100 & 4.0 & 20.0 & & \\
\hline & RR Total Index & 0 & 22.0 & 0.3 & 1.6 & & \\
\hline \multirow{4}{*}{ 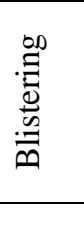 } & BL FS-Index & 20.0 & 60.0 & 20.0 & 0 & 0 & 20.0 \\
\hline & BL B-Index & 36.0 & 68.0 & 8.0 & 52.0 & 4.0 & 16.0 \\
\hline & BL Total Index & 26.1 & 63.0 & 15.4 & 19.8 & 1.5 & 18.5 \\
\hline & UC Total Index & 12.0 & 53.0 & 13.0 & 47.0 & 5.0 & 6.0 \\
\hline
\end{tabular}

Determination of Relative Contributions of Total Defect Indices to the Product Total Performance Index

Total Performance Index Based on the Data Itself - The premise underlying the development of the Total Performance Index is that the potential maximum value should be the same for all generic types of product. In each case, the sum of the derived decimal fraction coefficients must be unity and the potential maximum value of the Total Performance Index is again 100.

(a) Aluminum specimens - There are three types of defect: White Corrosion Products, Blistering and Undercutting. From the database, the mean overall respective total indices over 30 specimens are as follows: $\mathrm{WCPI}_{\mathrm{TOT}}=10.9, \mathrm{BLI}_{\mathrm{TOT}}=6.4, \mathrm{UCI}_{\mathrm{TOT}}=$ 4.1. The same procedure of normalization is followed dividing each of the indices into the highest value (10.9) to yield coefficients of 1.00, 1.70 and 2.68, which are normalized to decimal fractions $0.19,0.31,0.50$ (adding up to 1 ) by multiplying by 0.1859 
$[1 /(1.00+1.70+2.68)]$. The overall

relationship for the Total Performance

Index based on the data is:

$$
\mathrm{TPI}(\text { aluminum })=0.19 \mathrm{WCPI}_{\mathrm{TOT}}+0.31 \mathrm{BLI}_{\mathrm{TOT}}+0.50 \mathrm{UCI}_{\mathrm{TOT}}
$$

(b) Stainless steel + organic topcoat - There are three types of defect: Red Rusting, Blistering and Undercutting. From the database, the mean overall respective total indices (6 specimens) are as follows: $\mathrm{RRI}_{\mathrm{TOT}}=2.0, \mathrm{BLI}_{\mathrm{TOT}}=0, \mathrm{UCI}_{\mathrm{TOT}}=0.2$. The procedure of normalisation fails in this case as coefficients of $1, \infty$ and 10 would be obtained. No blistering occurred on the specimens, and one specimen had an undercutting rating of 1 on one feature. The total index for red rust at the stage as exampled in Table 10 was used for the total performance index.

(c) Metallic-coated steel + organic topcoat - There are four types of defect: White Corrosion Products, Red Rusting, Blistering and Undercutting. From the database, the mean overall respective total indices over 66 specimens are as follows: $\mathrm{WCPI}_{\mathrm{TOT}}=22.5$, $\mathrm{RRI}_{\mathrm{TOT}}=4.8, \mathrm{BLI}_{\mathrm{TOT}}=18.0, \mathrm{UCI}_{\mathrm{TOT}}=16.0$. The procedure of normalization yields equivalent coefficients of $1.00,4.68,1.25$ and 1.41 which are normalized to decimal fractions $0.12,0.56,0.15$ and 0.17 by multiplying by $0.12[1 /(1.00+4.68+1.25+1.41)]$. The overall relationship for the Total Performance Index based on the data is:

$$
\begin{aligned}
\text { TPI (metallic/org-coated steel) }= & 0.12 \mathrm{WCPI}_{\mathrm{TOT}}+0.56 \mathrm{RRI}_{\mathrm{TOT}} \\
& +0.15 \mathrm{BLI}_{\mathrm{TOT}}+0.17 \mathrm{UCI}_{\mathrm{TOT}}
\end{aligned}
$$

(d) Metallic-only-coated steel - There are two types of defect: White Corrosion Products and Red Rusting. From the database, the mean overall respective total indices over 18 specimens are as follows: $\mathrm{WCPI}_{\mathrm{TOT}}=47.5, \mathrm{RRI}_{\mathrm{TOT}}=10.3$. The procedure of normalization yields coefficients of 1.00 and 4.62 which are normalized to decimal fractions $0.18,0.82$ by multiplying by $0.178[1 /(1.00+4.62)]$. The relationship for the Total Performance Index based on the data is:

$$
\text { TPI (metallic-only-coated steel) }=0.18 \mathrm{WCPI}_{\mathrm{TOT}}+0.82 \mathrm{RRI}_{\mathrm{TOT}}
$$

Total Performance Index Based on the Judgments of Industry Representatives Eleven industry representatives were asked to assign coefficients (between 0 and 1) to describe the relative importance of the four types of defect on each of the four generic types of product. It was stated that no assignment was to be made for Red Rusting on aluminum, White Corrosion Product on stainless steel, or Blistering and Undercutting on metallic-only-coated steel, and also that the sum of the coefficients must be unity. The averages of the values together with the coefficients derived from the data are given in Table 11 . The equations based on the 12 sets of coefficients were used to calculate 12 sets of Total Performance Indices using the spreadsheet.

\section{Results and Discussion}

Space precludes a detailed presentation and analysis of the results from this project. Table 12 presents as an example the Total Performance Indices for the same 6 product/exposure condition combinations as previously (see Table 4). 
Table 11 - Coefficients for Relative Contribution of Defect Types to Total Performance Index

\begin{tabular}{|c|c|c|c|c|c|c|c|c|}
\hline $\begin{array}{c}\text { Defect } \\
\text { Type }\end{array}$ & \multicolumn{2}{|c|}{ Aluminum } & \multicolumn{2}{c|}{$\begin{array}{c}\text { Stainless Steel } \\
\text { + Organic Topcoat }\end{array}$} & \multicolumn{2}{c|}{$\begin{array}{c}\text { Metallic-coated } \\
\text { Steel + Organic } \\
\text { Topcoat }\end{array}$} & \multicolumn{2}{c|}{$\begin{array}{c}\text { Metallic-only- } \\
\text { coated Steel }\end{array}$} \\
\cline { 2 - 9 } & $\begin{array}{c}\text { Average } \\
\text { of } 11 \\
\text { Opinions }\end{array}$ & $\begin{array}{c}\text { Based } \\
\text { on } \\
\text { Data }\end{array}$ & $\begin{array}{c}\text { Average } \\
\text { of } 11 \\
\text { Opinions }\end{array}$ & $\begin{array}{c}\text { Based } \\
\text { on } \\
\text { Data }\end{array}$ & $\begin{array}{c}\text { Average } \\
\text { of } 11 \\
\text { Opinions }\end{array}$ & $\begin{array}{c}\text { Based } \\
\text { on } \\
\text { Data }\end{array}$ & $\begin{array}{c}\text { Average } \\
\text { of } 11 \\
\text { Opinions }\end{array}$ & $\begin{array}{c}\text { Based } \\
\text { on } \\
\text { Data }\end{array}$ \\
\hline WCP & 0.336 & 0.19 & & & 0.159 & 0.12 & 0.341 & 0.18 \\
\hline RR & & & 0.541 & & 0.409 & 0.56 & 0.659 & 0.82 \\
\hline BL & 0.395 & 0.31 & 0.259 & & 0.232 & 0.15 & & \\
\hline UC & 0.268 & 0.50 & 0.200 & & 0.200 & 0.17 & & \\
\hline
\end{tabular}

Table 12 - Total Performance Indices for 3 Products with Polyester or SMP Topcoats

\begin{tabular}{llcccccc}
\hline \multicolumn{1}{c}{ TPI } & & I112O & I112S & B512O & B512S & C412O & C412S \\
\hline Calculated from data & & 11.2 & 40.2 & 6.5 & 15.8 & 4.3 & 12.0 \\
Calculated from & Ave. & 15.4 & 46.2 & 8.5 & 19.5 & 4.3 & 14.4 \\
11 industry opinions & Min. & 10.8 & 39.0 & 6.0 & 12.9 & 3.3 & 12.0 \\
& Max. & 20.8 & 55.5 & 12.6 & 32.8 & 5.6 & 16.5 \\
\hline
\end{tabular}

This data shows that the aluminum-based product (C4) is the best overall performer (TPIs are low) of these three (with polyester paint topcoats). Also, good agreement exists between the TPI calculated from the data and the average TPI for 11 industry opinions. The action of the shelter in markedly accelerating the deterioration of products is apparent, with the sheltered indices being 3 to 4 times those of the open indices.

\section{Agreement Between Performance Indices Calculated from Data and Industry Opinions}

Exceptional agreement has been obtained between the total performance indices calculated from the data and those based on the judgments of the 11 industry representatives as to the relative importance of different defect types for each generic class of product. A plot of the average industry opinion TPIs against that calculated from the data is given in Figure 2. A linear regression forced through the origin has a slope of 1.16 (standard error 0.01) and an R-squared value of 0.98 . There was great variation in the TPIs among the 11 opinions though. Across the 120 product/exposure condition combinations the ratio of the maximum industry opinion TPI to the corresponding minimum was on average 3.1 , with a range of 1.1 to 8 . This clearly demonstrates that the procedure developed in this paper to use the data itself has overcome the drawback of one individual subjectively assigning weighting factors to the relative importance of various defects and features.

\section{Comparative Performance of Generic Classes of Products}

The performance of individual products or classes of products can be assessed by comparing either the Total Performance Indices (TPIs) or the relative rankings. If the aim is to get an overall assessment across several sites of different severity, the use of rankings may be preferable as all sites and conditions (open and sheltered) will contribute equally. If TPIs are used there is a very great difference between the results from the sheltered severe site and the open benign site and the former results will "skew" an overall assessment. To this end, a file with TPIs calculated from the data was sorted 
(from low to high) for each of the

sites/conditions in turn. A ranking from 1 to 20 was added in each case. These rankings were summed for each of the products, separately for open and sheltered exposures (3 cases, i.e. 3 sites for each). A plot of the summed rankings sheltered versus open is given in Figure 3; again low values represent the best performers. At the bottom left of the plot $\mathrm{PVF}_{2}$ painted 304 stainless steel (B4), $\mathrm{PVF}_{2}$ painted (with $25 \mu \mathrm{m}$ primer) 55\% Al-Zn (B7), PVF laminated galvanized steel (I6), and aluminum painted with $\mathrm{PVF}_{2}$ (C1), polyester (C4) and urethane X link polyester (C3) are performing best considering both open and sheltered exposures. Considering open exposure only, unpainted $55 \% \mathrm{Al}-\mathrm{Zn}$ and polyester painted $55 \% \mathrm{Al}-$ Zn (B1 and B5 respectively), and polyester painted 5\% Al-Zn (I1), are also better performers. See Table 2 of Ref. 2 for full identification and specification details of all products.

The TPIs from the data itself for the severe marine site are shown in Figure 4 grouped into generic classes. Again the stainless steel product and those based on aluminum are performing very well considering both open and sheltered exposures. 


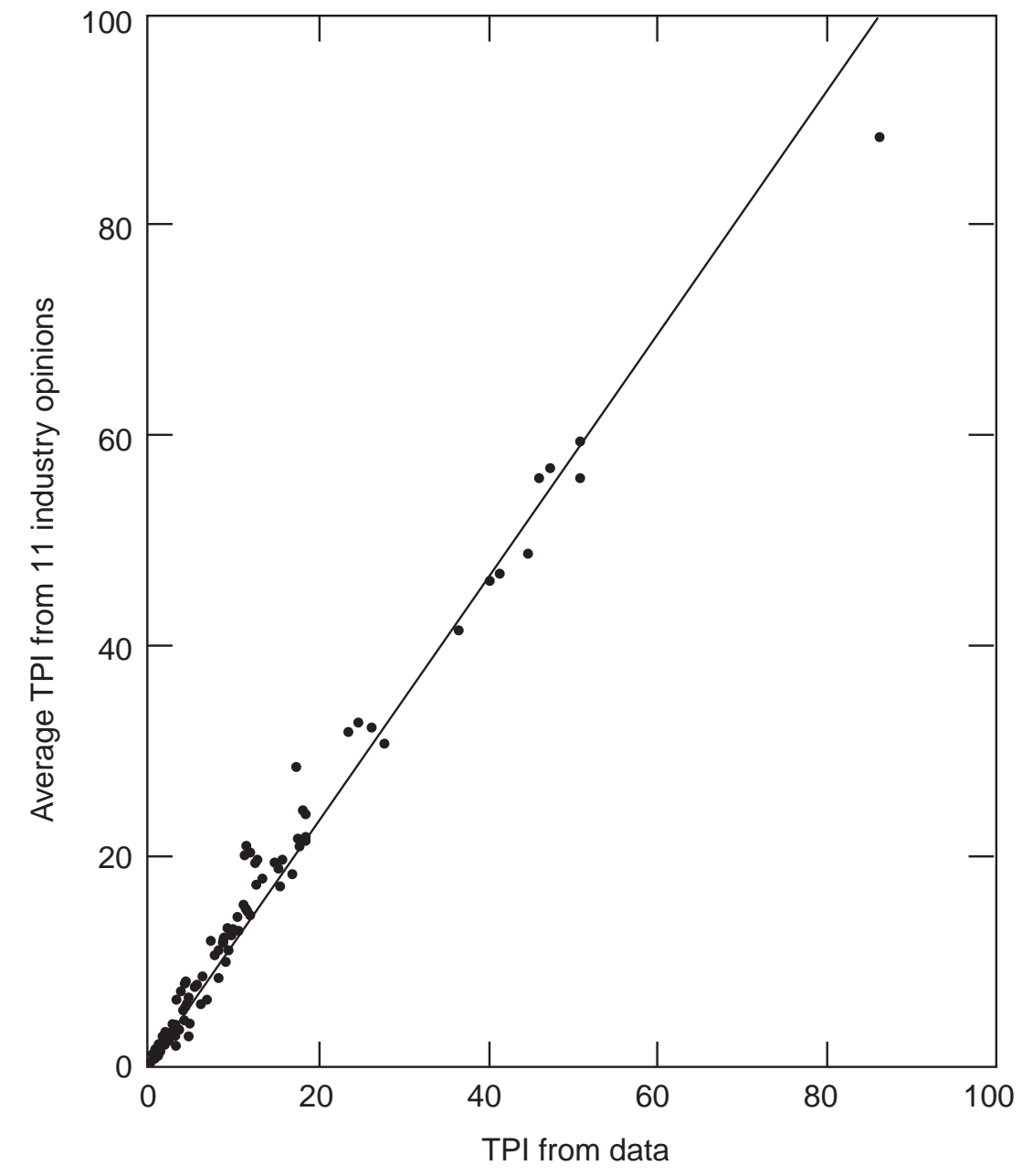

Figure 2 - Total Performance Indices from Average of 11 Industry Opinions Versus that Calculated from the Data (Two-year Data)

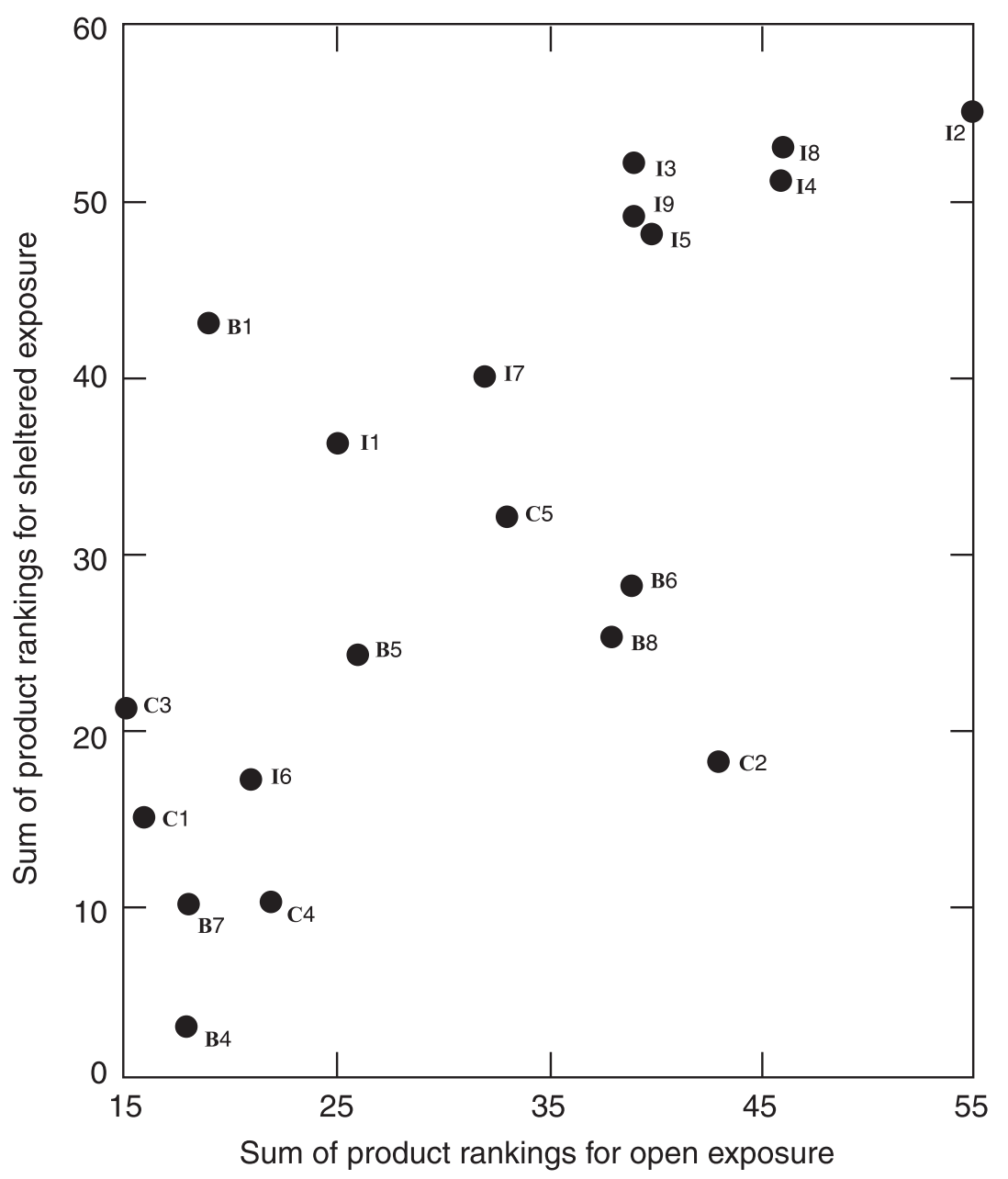

Figure 3 - Sum of Comparative Rankings for Each of 20 Products Exposed at Three Sites for Two Years 


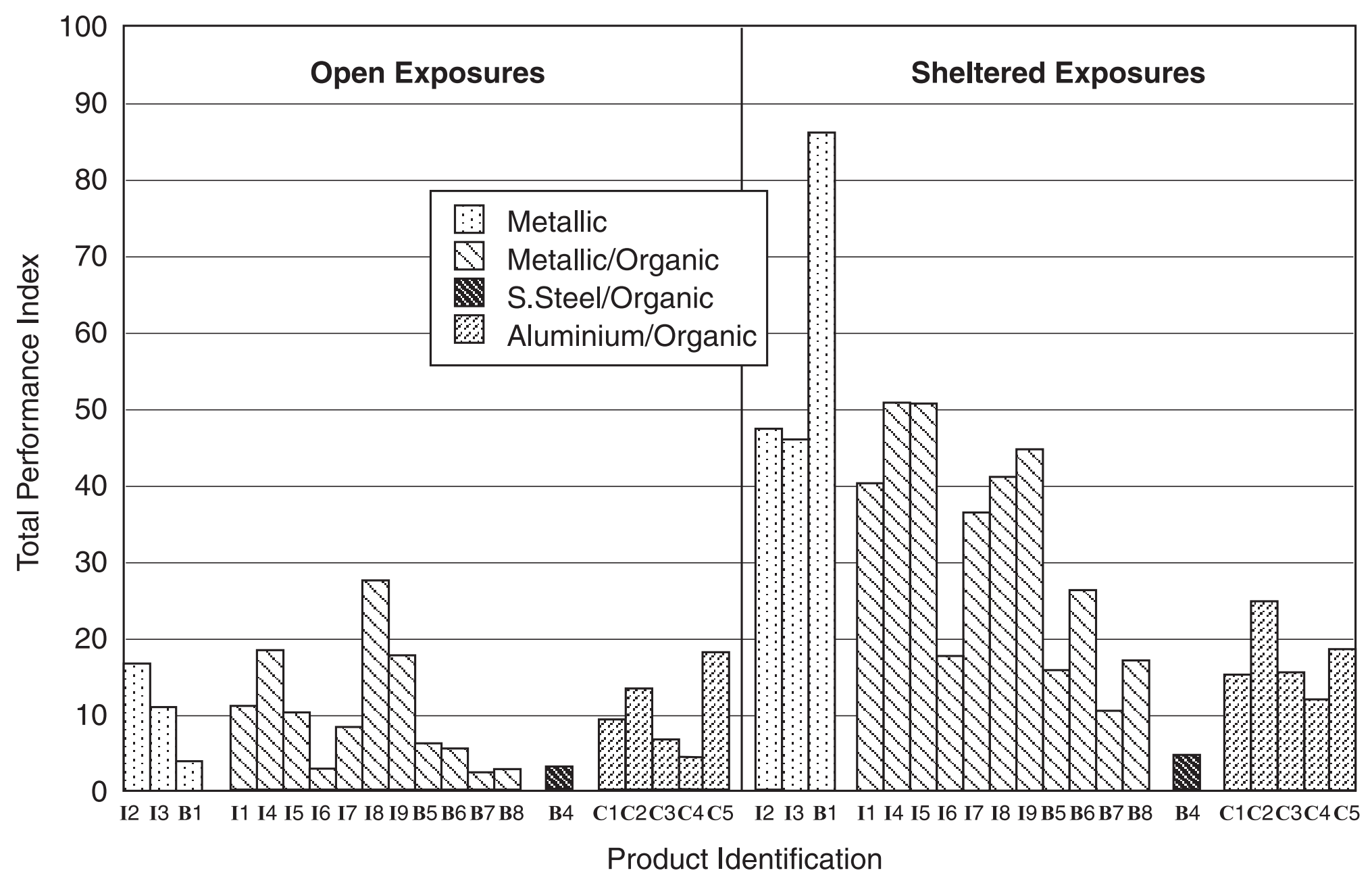

Figure 4 - Total Performance Indices for All Products at Severe Marine Site (Navy Base) Based on Data Only 
Action of the Sheltering System in Accelerating Deterioration

For the example given above, the action of the shelters in markedly accelerating the deterioration of products was apparent. Across all of the 20 products the ratios of the sheltered to open TPIs (from the data) were as follows (average followed by min. and max. in parentheses): severe marine site $4.0(1.0,20.2)$, moderate marine/rural site 7.2 $(0.6,21.9)$, mild marine/urban site $6.0(1.2,17.2)$. These figures represent very significant increases in the rates of deterioration compared to products in open exposure. Future papers will discuss the relationships that exist between sheltered and open exposures in terms of defect types as well as total performance, and compare the results from different exposure periods to determine how well sheltered short-term exposures predict the performance for longer term open exposures.

Measurements of air temperature and relative humidity, and also estimates of time of wetness according to ISO 9223 Corrosion of Metals and Alloys - Corrosivity of Atmospheres - Classification, have shown that at the severe marine sites no significant differences exist between the conditions prevailing in the open and those under the specially designed shelter [5]. In contrast, direct measurements of time of wetness and surface temperature using the Scandinavian WETCORR technique [6] have revealed that the actual time of wetness is much longer under the shelter. This is consistent with the observed differences in corrosion rates between the open and sheltered exposures. The mechanism is not yet fully understood but definitely involves the fact that deposited sea salt accumulates with time and never gets an opportunity to be washed off during rain periods [5].

\section{Conclusions}

A methodology for determining objective quantitative indices to describe the atmospheric corrosion performance of coated metal sheet products has been developed. Analysis of the indices in conjunction with those produced by using subjective opinions from industry representatives, has demonstrated that the new technique can accurately describe and quantify performance. A means is available for a more rigorous and numerical analysis of corrosion performance in an area hitherto often descriptive. A novel semi-sheltered exposure system has been shown to induce highly accelerated deterioration of sheet products, with factors on average from four to seven times comparing indices for sheltered and open exposures.

\section{Acknowledgments}

BHP Research (Coated Products Division) and the International Lead Zinc Research Organisation Inc. (ILZRO) for ongoing financial support and Comalco Aluminium Ltd for prior support of the project. RAN HMAS Cerberus and Mornington Peninsula and District Water Boards for their cooperation in establishing exposure racks within their grounds. David O’Brien, Natalie Sherman and Pon Kao of CSIRO for technical assistance. Mary Cope of CSIRO for the word processing of this document, Cathy Bowditch of CSIRO for editorial and Marie Scott of CSIRO for the figures. 


\section{References}

[1] Willis, D. J., "Performance of 55\% Al-Zn Coated Steel Sheets Used for Residential Houses in Australia,” Proc. 4th Int. Conf. on Zinc and Zinc Alloy Coated Steel Sheet (GALVATECH '98), The Iron and Steel Inst. of Japan, Chiba, Japan, 1998.

[2] King, G. A., and O’Brien, D. J., “The Influence of Marine Environments on Metals and Fabricated Coated Metal Products, Freely Exposed and Partially Sheltered,” Atmospheric Corrosion, ASTM STP 1239, W. W. Kirk and H. H. Lawson, Eds., American Society for Testing and Materials, West Conshohocken, PA, 1995, pp. 167-192.

[3] Tiemens, J. J., and Hoeflaak, M., "The Performance Level of Some Commercial Coil-Coated Materials,” Construction and Building Materials, Vol. 8, No. 4, pp. 243-259, 1994.

[4] Johnson, K., and Marsh, E., “A Study of Relationships Between Design of Precoated Steel Cladding and its Environmental Behaviour in Service,” Report EUR10715EN, Commission of the European Communities, 1987.

[5] Norberg, P., King, G., and O’Brien, D., "Corrosivity Studies and Microclimate Measurements in Marine Environments,” Proc. 35th Conf. of the Australasian Corrosion Association (Corrosion \& Prevention 95), Perth, Australia, 12-16 November 1995, Paper 36.

[6] Norberg, P., Proc. 6th Int. Conf. on Durability of Building Materials and Components, Omiya, 26-29 October 1993, pp. 637-646. 